\title{
Transfer of newborns to neonatal care unit: a registry based study in Northern Tanzania
}

Blandina T Mmbaga ${ }^{1,2,3^{*}}$, Rolv T Lie ${ }^{2,4}$, Gibson S Kibiki ${ }^{1,5}$, Raimos Olomi ${ }^{1}$, Gunnar Kvåle ${ }^{3}$ and Anne K Daltveit ${ }^{2,4}$

\begin{abstract}
Background: Reduction in neonatal mortality has been slower than anticipated in many low income countries including Tanzania. Adequate neonatal care may contribute to reduced mortality. We studied factors associated with transfer of babies to a neonatal care unit (NCU) in data from a birth registry at Kilimanjaro Christian Medical Centre (KCMC) in Tanzania.
\end{abstract}

Methods: A total of 21206 singleton live births registered from 2000 to 2008 were included. Multivariable analysis was carried out to study neonatal transfer to NCU by socio-demographic factors, pregnancy complications and measures of the condition of the newborn.

Results: A total of 3190 (15\%) newborn singletons were transferred to the NCU. As expected, neonatal transfer was strongly associated with specific conditions of the baby including birth weight above $4000 \mathrm{~g}$ (relative risk (RR) = 7.2; $95 \%$ confidence interval (Cl) 6.5-8.0) or below $1500 \mathrm{~g}(\mathrm{RR}=3.0 ; 95 \% \mathrm{Cl}: 2.3-4.0$ ), five minutes Apgar score less than 7 (RR $=4.0 ; 95 \% \mathrm{Cl}: 3.4-4.6)$, and preterm birth before 34 weeks of gestation (RR $=1.8 ; 95 \% \mathrm{Cl}: 1.5-2.1)$. However, pregnancy- and delivery-related conditions like premature rupture of membrane (RR $=2.3 ; 95 \%$ Cl: 1.9 2.7), preeclampsia ( $R R=1.3 ; 95 \% \mathrm{Cl}: 1.1-1.5)$, other vaginal delivery $(\mathrm{RR}=2.2 ; 95 \% \mathrm{Cl}: 1.7-2.9)$ and caesarean section $(\mathrm{RR}=1.9 ; 95 \% \mathrm{Cl}: 1.8-2.1)$ were also significantly associated with transfer. Birth to a first born child was associated with increased likelihood of transfer (relative risk (RR) 1.4; $95 \% \mathrm{Cl}$ : 1.2-1.5), while the likelihood was reduced (RR = 0.5; 95\% Cl: 0.3-0.9) when the father had no education.

Conclusions: In addition to strong associations between neonatal transfer and classical neonatal risk factors for morbidity and mortality, some pregnancy-related and demographic factors were predictors of neonatal transfer. Overall, transfer was more likely for babies with signs of poor health status or a complicated pregnancy. Except for a possibly reduced use of transfer for babies of non-educated fathers and a high transfer rate for first born babies, there were no signs that transfer was based on non-medical indications.

\section{Background}

Progress on United Nations' Millennium Development Goal 4 (MDG4) to reduce the under-five mortality has been slower than anticipated due to high neonatal mortality in developing countries. Worldwide, about 4 million neonatal deaths occur each year, of these three quarter occur in the first week of life with the highest risk at the first day of life [1]. Estimated neonatal mortality in Tanzania is about 35 per 1000 live births, and neonatal deaths are estimated to account for $28 \%$ of the under-five mortality [2]. Both the infant mortality rate

\footnotetext{
* Correspondence: blaymt@yahoo.com

${ }^{1}$ Kilimanjaro Christian Medical Centre and Kilimanjaro Christian Medical

College, P.O Box 3010, Moshi, Tanzania

Full list of author information is available at the end of the article
}

and the under -five mortality rate have decreased from 1990 to 2004; by 31\% (from 99 to 68 deaths per 1000 live births) and 24\% (from 147 to 112 deaths per 1000 live births), respectively. This decline was, however, observed for post-neonatal mortality only, while neonatal as well as maternal mortality remained unchanged $[2,3]$. Adequate neonatal care may therefore be an important factor for continued improvement. Socio-economic deprivations are known to cause poor perinatal outcome such as neonatal care admission [4-7], low birth weight [8-10] and increased perinatal mortality [10-13]. A review of international evidence in socio-economic inequalities in childhood mortality in low and middle income countries showed higher childhood mortality in low socio-economic groups within each country

\section{Biomed Central}


[14]. Absolute inequalities were found to be higher for infant mortality than for child mortality. It was also estimated that $20-25 \%$ of under-five mortality inequalities arise in the neonatal period [14]. Making sure that health care is provided independent of social status is important for overall improvement in health.

Most studies on neonatal health in developing countries have focused on mortality rather than morbidity. However, in order to reduce neonatal mortality it is also of importance to consider factors associated with neonatal morbidity. Transfer of babies to neonatal care unit (NCU) may represent an indicator of morbidity that can be used for designing and implementing interventions aimed at improving health and increasing neonatal survival. Although previous studies have reported on the relationship of socio-demographic, maternal, or neonatal factors with neonatal admission $[5,6,15]$, the combined effect of socio-demographic, maternal health factors and neonatal factors in relation to admission to NCU has not been well explored.

Referral in pregnancy and child birth can be categorised as self-referral or referral performed by health workers [16]. Self-referral implies that a woman (perhaps with the help of her family) seeks care at a health centre or a hospital. A study of 415 maternity admissions in Tanzania found that about $70 \%$ of the admissions could be categorized as self-referrals [16].

The presence of a NCU at the hospital gives an opportunity for all at risk babies to be admitted and managed by a paediatrician. The paediatric department at KCMC has established guidelines for care and management of newborns based on the condition of the newborn. Decision for transfer is usually done by midwives or a paediatrician based on the condition of the newborn; low Apgar score, prematurity, birth weight $<1800$ or birth weight $>4000$ g, congenital malformation and suspected infection. In addition, some obstetric conditions may necessitate baby transfer because they could represent a risk to the newborn. When a pregnancy complication indicates that the baby needs to be seen by a paediatrician, the paediatrician is informed in advance and attends the delivery to take care of the newborn in the labour ward or in NCU if transfer is necessary. The parents are usually informed about the reason for babies transfer but they are not asked for decision. Although KCMC is a private hospital, payment for the hospital bill is not considered as initial criteria for transfer or management of admitted newborns, therefore, all admitted babies receive same quality of care irrespective of the social background. The social welfare department within the hospital usually takes care of the hospital bills for families unable to pay.

The aim of our analysis was to estimate the influence of social background, pregnancy-related conditions and the condition of the newborn in relation to neonatal transfer to NCU. We explore these associations in a structured series of analyses, expecting most of the associations to be explained by the condition of the newborn. First, we expect social conditions to impact the likelihood of transfer by their effects on pregnancy complications and the condition of the newborn. Then we expect pregnancy complications to impact the likelihood of transfer by their effects on the condition of the newborn. Deviations from these expectations will appear as residual effects of social background and pregnancy complications after we adjust for the condition of the newborn. Such deviations will be inspected further since they could represent priority-settings or clinical judgment that incorporates social background or the background history of the delivery.

\section{Methods \\ Setting}

This study was done at Kilimanjaro Christian Medical Centre (KCMC) in Northern Tanzania. The hospital is a zonal hospital serving more than 13 million people from 4 regions namely; Kilimanjaro, Arusha, Tanga and Manyara. We established a cohort of babies based on records from the Medical Birth Registry comprising all deliveries at the hospital from July 2000 to September 2008 and followed the cohort in a registry of neonates transferred from the labour ward to NCU. The KCMC Medical Birth Registry system was established in 1999 as a collaboration between Kilimanjaro Christian Medical College, Tumaini University and the University of Bergen, Norway. The annual number of deliveries is around 3000 of which nearly two thirds are from urban area. Approximately $10-15 \%$ of the neonates are transferred to NCU for observation and management.

A total of 26025 births were recorded in the Medical Birth Registry from July $1^{\text {st }} 2000$ to September $30^{\text {th }} 2008$. We excluded multiple deliveries, stillbirths, neonatal deaths in labour ward and neonates with missing child status record after delivery (Figure 1). In order to obtain a study group that reflected the general population, we excluded deliveries where mothers residing in rural areas had been referred for delivery at KCMC for medical reasons. Women residing in Moshi urban were not excluded since they could have delivered at KCMC anyway. $\mathrm{KCMC}$ is located in Moshi Urban and that $50 \%$ of the deliveries at KCMC are from Moshi Urban district [11]. We finally analyzed a total of 21206 singleton live births.

\section{Data collection}

Information from all mothers who delivered at KCMC were collected within the first 24 hours after delivery. Trained midwife nurses conducted the interviews on a daily basis with all eligible subjects using a standardized 


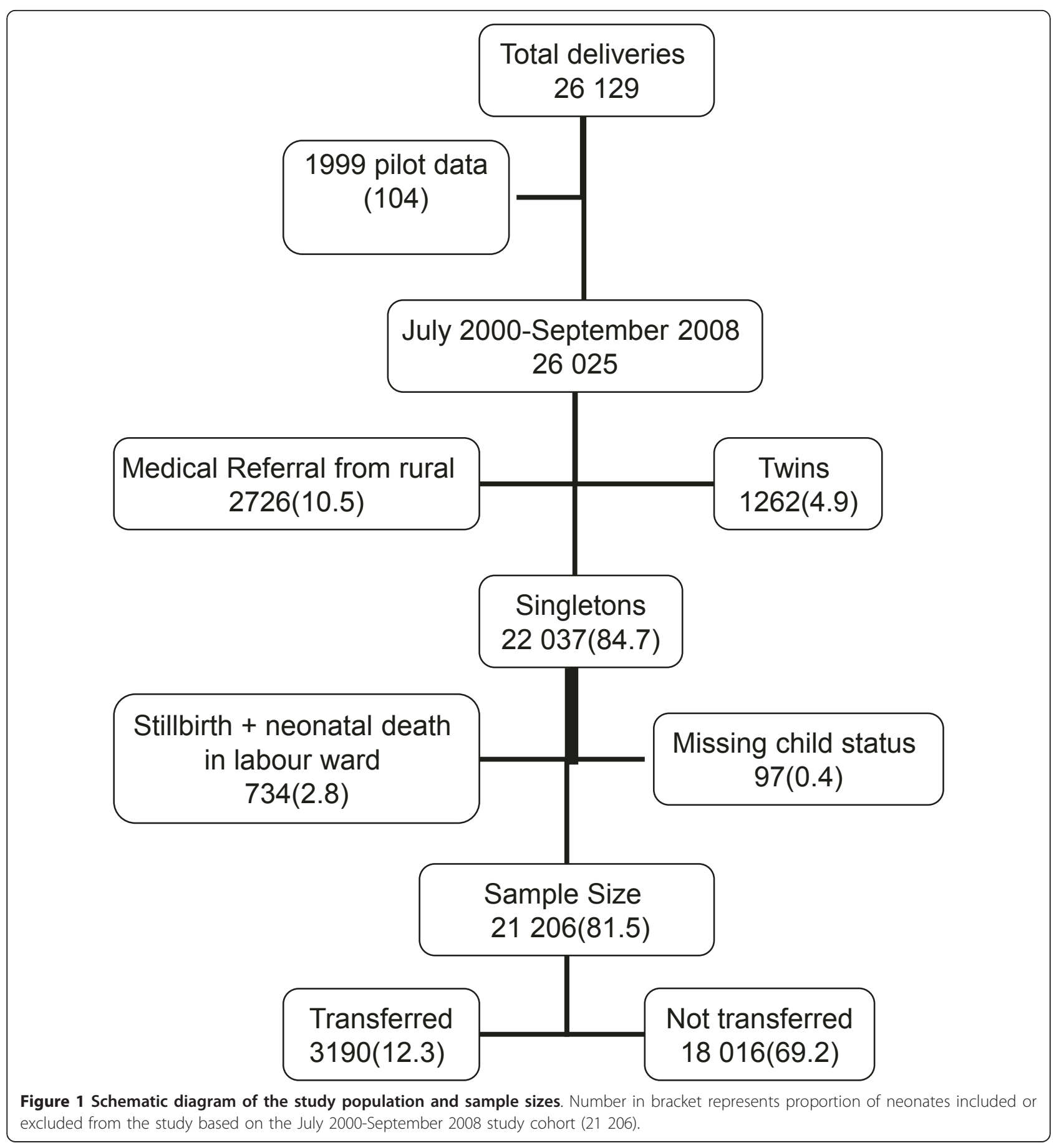

questionnaire. A verbal consent was obtained from the participants prior to the interview. Mothers also provided their antenatal visit card for more information such as date of first ANC visit, immunization history, malaria prophylaxis, drugs, illnesses recorded during follow up, weight at first ANC visit, number of ANC visits, as well as referral to ANC (self-referred or referred by health worker).
Information in the birth registry includes maternal health conditions before and during pregnancy, parents' socio-demographic characteristics, complications during labour and delivery, and information on the newborn; sex, gestational age, birth weight, Apgar score, and child status in four categories: 1) live born 2) live born transferred to NCU 3) neonatal death in labour ward, 4) stillborn. 
The paediatric registry form was recorded in the NCU for all neonates who were transferred. The neonatal registry includes information on primary reasons for transfer, management, and discharge/death diagnoses. The two databases were linked using the unique child identification number, the mother's hospital registration, and the newborn's birth registration number.

\section{Variable definition}

Transfer to NCU was the main outcome. Independent variables include socio-demographic characteristics including maternal, paternal and environmental factors, maternal health conditions before and during pregnancy, and complications during labour and delivery, as well as condition of the newborn (Tables 1, 2 and 3).

\section{Data analysis}

Data were analyzed using Statistical Package for Social Science (SPSS) program Version 15.0 for Windows (SPSS 15.0 Chicago Inc. III, USA). Cross tabulations and generalized linear models were used to obtain relative risks (RR) and corresponding 95\% confidence intervals. From the bivariate analyses we present all variables with p-value less than 0.1 , which were then entered into the multivariable analysis. Three steps were involved in the multivariable analysis. In the first step (model A) all socio-demographic factors and maternal health condition before pregnancy were included. In the second step (model B) we included all variables in step one as well as pregnancy and labour-related conditions. In the third and final step (model $\mathrm{C}$ ), we included all variables in step two as well as neonatal conditions. We used Poisson regression with robust variances to obtain a valid confidence interval when a log-binomial analysis failed to converge [17]. A priori we also considered some maternal conditions to be important and included in the final analysis, these were hypertensive conditions (preeclampsia, eclampsia and abruption placenta) and diabetes (pre-gestational or gestational).

\section{Ethical approval}

The birth registry at Kilimanjaro Christian Medical Centre obtained ethical clearance from the Tanzania Ministry of Health, Institute of Science and Technology, from the Norwegian National ethics committee and from the Kilimanjaro Christian Medical College (KCM-College) research ethics committee in 1999. The protocol for this study was approved by KCM-College research ethics committee, with certificate no. 333 of $15^{\text {th }}$ July 2010.

\section{Results}

A total of 21206 live-born singletons were analysed. The majority of the mothers were married (89.7\%), were residing in urban areas (61.9\%), had primary school education (61.3\%), and belonged to the Chagga tribe (58.2\%). Mean maternal age at child birth was 27.4 (SD $=6.1$ ) years, and $38.8 \%$ of the mothers had their first born child. Mean maternal pre-pregnancy weight and height were $62.7(\mathrm{SD}=12.5)$ kilograms and $160.0(\mathrm{SD}=$ $6.7)$ centimetres, respectively. The mean number of antenatal care visits per women was $5(\mathrm{SD}=2.1)$. Mean gestational age and birth weight were $39.1(\mathrm{SD}=2.5)$ weeks and 3090 (SD = 544 grams), respectively.

A total of 3190 (15\%) were transferred to NCU. Descriptive associations between transfer and sociodemographic, pregnancy-related and neonatal factors are shown in Tables 1,2 and 3.

\section{Socio-demographic characteristics and pre pregnancy conditions}

After mutual adjustment of the socio-demographic and maternal pre-pregnancy health factors, most of the factors remained associated with neonatal transfer (Table 4; model A). First born babies and fourth or later born babies (RR 1.3; 95\% CI: $1.2-1.4$ and 1.2; 95\% CI: 1.0-1.3, respectively) were shown to have a high risk of being transferred compared with second born babies. Babies of single mothers were more likely to be transferred compared to babies of married mothers (RR 1.3; 95\% CI: 1.1-1.5). Both maternal overweight and obesity increased the risk of babies transfer. Babies born from families who do not boil water for drinking had increased risk of being transferred to NCU (RR 1.2; 95\% CI: 1.1-1.3).

Pre-gestational diabetes mellitus was strongly associated with neonatal transfer to NCU (RR 4.4; 95\% CI: 3.3-5.8). A history of acute or chronic lung disease other than tuberculosis showed a weaker association (RR 1.2; 95\% CI: 1.1-1.4).

\section{Pregnancy, labour and delivery}

Factors related to pregnancy, labour and delivery were included in the multivariable model in B. Hypertensive conditions such as eclampsia and preeclampsia (RR 2.8; 95\% CI:1.7-4.4 and 2.0; 95\% CI: 1.7-2.3, respectively), labour-related complications such as premature rupture of membrane and abruption placenta (RR 2.9; 95\% CI: 2.6-3.4 and 2.6; 95\% CI: 1.6-4.1, respectively), and other vaginal delivery (i.e. breech, vacuum or forceps) and caesarean section delivery (RR 2.9; 95\% CI: 2.3-3.6 and 2.1; 95\% CI: 1.9-2.3, respectively) were all associated with transfer (Table 4; model B). Gestational diabetes increased the risk of babies transfer by $40 \%$ although not statistically significant. Referral to ANC and few ANC visits were also found to be important predictors of neonatal transfer to NCU (RR 1.3; 95\% CI: 1.1-1.4 and $1.3 ; 95 \% \mathrm{CI}: 1.2-1.4)$, respectively. 
Table 1 Transfer to neonatal care unit $(n=3190)$ among 21206 live-born according to socio-demographic factors

\begin{tabular}{|c|c|c|c|c|}
\hline Risk factors & $\begin{array}{l}\text { Number } \\
\text { live-born } \\
\text { deliveries }\end{array}$ & $\begin{array}{l}\text { Proportion (\%) } \\
\text { live-born babies } \\
\text { transferred to NCU }\end{array}$ & RR $(95 \% \mathrm{Cl})$ & $\mathrm{p}$-value \\
\hline \multicolumn{5}{|l|}{ Maternal factors ${ }^{\mathrm{x}}$} \\
\hline Maternal age (years) & & & & 0.106 \\
\hline Under 18 & 480 & 17.9 & $1.2(1.0-1.5)$ & \\
\hline $18-25$ & 8328 & 14.5 & 1.0 & \\
\hline $26-35$ & 10272 & 15.3 & $1.0(1.0-1.1)$ & \\
\hline Over 35 & 2070 & 15.7 & $1.0(1.0-1.2)$ & \\
\hline Mother's tribe & & & & 0.032 \\
\hline Chagga & 12311 & 14.5 & 1.0 & \\
\hline Pare & 2496 & 16.2 & $1.0(1.0-1.2)$ & \\
\hline Others & 6355 & 15.6 & $1.0(1.0-1.2)$ & \\
\hline Marital status & & & & $<0.0001$ \\
\hline Married & 19016 & 14.6 & 1.0 & \\
\hline Single & 2086 & 18.6 & $1.3(1.2-1.4)$ & \\
\hline Birth order & & & & $<0.0001$ \\
\hline $1^{\text {st }}$ Child & 8220 & 16.4 & $1.2(1.1-1.3)$ & \\
\hline $2^{\text {nd }}$ Child & 5985 & 13.4 & 1.0 & \\
\hline $3^{\text {rd }}$ Child & 3287 & 16.5 & $1.0(0.9-1.1)$ & \\
\hline $4^{\text {th }}$ or more & 3714 & 13.5 & $1.2(1.1-1.4)$ & \\
\hline Mother's education & & & & 0.060 \\
\hline No education & 348 & 17.8 & $1.2(1.0-1.7)$ & \\
\hline Primary & 12990 & 15.3 & $1.0(1.0-1.1)$ & \\
\hline Sec/higher & 7819 & 14.4 & 1.0 & \\
\hline Mother's occupation & & & & $<0.0001$ \\
\hline Professional & 3355 & 14.3 & 1.0 & \\
\hline Business & 4821 & 14.8 & $1.0(0.9-1.2)$ & \\
\hline Service & 1538 & 15.4 & $1.1(0.9-1.2)$ & \\
\hline Farmer & 4003 & 16.3 & $1.1(1.0-1.3)$ & \\
\hline Housewife & 5401 & 15.4 & $1.1(1.0-1.2)$ & \\
\hline Others & 1955 & 13.3 & $1.0(0.8-1.1)$ & \\
\hline Body height (cm) & & & & $<0.0001$ \\
\hline$<150$ & 1505 & 18.3 & $1.4(1.2-1.5)$ & \\
\hline $150+$ & 18342 & 14.1 & 1.0 & \\
\hline $\mathrm{BMI}\left(\mathrm{kg} / \mathrm{m}^{2}\right)$ & & & & 0.013 \\
\hline$<18.5$ & 1277 & 14.1 & $1.1(0.9-1.2)$ & \\
\hline $18.5-24.9$ & 4787 & 14.8 & 1.0 & \\
\hline $25-29.9$ & 6793 & 13.3 & $1.1(1.0-1.2)$ & \\
\hline $30+$ & 1496 & 16.2 & $1.2(1.1-1.4)$ & \\
\hline Genital mutilation & & & & 0.086 \\
\hline Yes & 4752 & 15.8 & $1.0(0.9-1.0)$ & \\
\hline No & 16389 & 14.8 & 1.0 & \\
\hline Drinking in pregnancy & & & & 0.033 \\
\hline Yes & 8278 & 14.4 & 1.0 & \\
\hline No & 12882 & 15.4 & $1.1(1.0-1.2)$ & \\
\hline \multicolumn{5}{|l|}{ Paternal factors ${ }^{x}$} \\
\hline Father's age (years) & & & & 0.003 \\
\hline Under 26 & 3002 & 16.7 & $1.1(1.1-1.3)$ & \\
\hline $26-35$ & 11794 & 14.6 & 1.0 & \\
\hline $36-45$ & 5428 & 14.5 & $1.0(0.9-1.1)$ & \\
\hline Over 45 & 827 & 17.7 & $1.2(1.0-1.4)$ & \\
\hline
\end{tabular}


Table 1 Transfer to neonatal care unit $(n=3190)$ among 21206 live-born according to socio-demographic factors (Continued)

\begin{tabular}{|c|c|c|c|c|}
\hline Father's tribe & & & & 0.004 \\
\hline Chagga & 11157 & 14.2 & 1.0 & \\
\hline Pare & 2463 & 16.0 & $1.1(1.0-1.3)$ & \\
\hline Others & 7451 & 15.8 & $1.1(1.0-1.2)$ & \\
\hline Father's Occupation & & & & $<0.0001$ \\
\hline Professional & 4483 & 14.0 & 1.0 & \\
\hline Business & 6798 & 14.8 & $1.1(1.0-1.2)$ & \\
\hline Service & 4321 & 15.0 & $1.1(1.0-1.2)$ & \\
\hline Farmer & 2070 & 18.7 & $1.3(1.2-1.5)$ & \\
\hline Skilled & 2808 & 14.1 & $1.0(0.9-1.1)$ & \\
\hline Others & 643 & 15.9 & $1.1(0.9-1.4)$ & \\
\hline Father's education & & & & 0.013 \\
\hline No education & 110 & 20.9 & $1.5(1.0-2.1)$ & \\
\hline Primary & 10563 & 15.5 & $1.1(1.0-1.2)$ & \\
\hline Sec/higher & 10446 & 14.4 & 1.0 & \\
\hline \multicolumn{5}{|c|}{ Environmental factors ${ }^{\times}$} \\
\hline Type of toilet & & & & 0.006 \\
\hline Pit latrine & 12515 & 15.6 & $1.1(1.0-1.2)$ & \\
\hline Flush & 8608 & 14.2 & 1.0 & \\
\hline Source of water & & & & 0.030 \\
\hline Tap water & 19555 & 14.9 & 1.0 & \\
\hline Well & 459 & 16.6 & $1.1(0.9-1.4)$ & \\
\hline River & 432 & 19.7 & $1.3(1.1-1.6)$ & \\
\hline Spring & 644 & 16.0 & $1.1(0.9-1.3)$ & \\
\hline Boil drinking water & & & & $<0.0001$ \\
\hline Yes & 6672 & 13.3 & & \\
\hline No & 14449 & 15.8 & $1.2(1.1-1.3)$ & \\
\hline
\end{tabular}

$\mathrm{x}$-The total in some variables does not sum to 21206 due to missing data

Significant factors in model A continued to be independent predictors for neonatal transfer also in model $\mathrm{B}$, except for maternal body height below $150 \mathrm{~cm}$. However, addition of variables in model B slightly reduced the relative risk for most factors.

\section{Neonatal factors}

In model $\mathrm{C}$, neonatal factors were added into the multivariable model. All the selected neonatal factors were significantly associated with transfer to NCU, with the highest relative risks being for birth weight above 4000 g (RR 7.2; 95\% CI: 6.5-8.0) and five minutes Apgar score below 7 (RR 4.0; 95\% CI: 3.4-4.6) (Table 4; model C).

After inclusion of the neonatal factors, some pre-pregnancy factors, such as women giving birth to their first babies (RR 1.4; 95\% CI: 1.2-1.5), maternal age 26-35 years (RR 1.2; 95\% CI: 1.1-1.3), and single marital status (RR 1.2; 95\% CI: 1.0-1.3) were still significantly associated with neonatal transfer. Lack of paternal education (RR: 0.5; 95\% CI: 0.3-0.9) was negatively associated with transfer to NCU. Birth to fourth or later born babies, maternal overweight or obesity, pre-gestational diabetes and epilepsy were no longer significantly associated with neonatal transfer.

\section{Discussion}

In this registry based study from a tertiary hospital in Tanzania, we identified patterns of neonatal transfer to NCU. In a three-step analysis we studied socio-demographic factors, maternal health factors, and neonatal factors in relation to transfer. A particular aim was to assess whether socio-demographic factors were related to transfer to NCU beyond their association with well-defined medical risks. The analyses showed that neonatal factors by far had the strongest association with neonatal transfer, but that pre-pregnancy and pregnancy factors were also independently associated with transfer.

The incidence of neonatal transfer in this study was 15\%, which is slightly higher than reported in previous studies both from developed $[4,5]$ and developing countries $[7,18]$.

\section{Neonatal factors}

The studied neonatal factors included classical risk factors for morbidity and mortality, such as birth weight, 
Table 2 Transfer to neonatal care unit $(n=3190)$ among 21206 live-born according to maternal health conditions

\begin{tabular}{|c|c|c|c|c|}
\hline Risk factors & $\begin{array}{l}\text { Number } \\
\text { live-born } \\
\text { deliveries }\end{array}$ & $\begin{array}{l}\text { Proportion (\%) } \\
\text { live-born babies } \\
\text { transferred to NCU }\end{array}$ & RR $(95 \% \mathrm{CI})$ & $\mathrm{p}$-value \\
\hline \multicolumn{5}{|l|}{ Before pregnancy $^{a}$} \\
\hline Medication regular & 493 & 18.9 & $1.3(1.1-1.5)$ & 0.013 \\
\hline Diabetes & 49 & 69.4 & $4.7(3.9-5.6)$ & $<0.0001$ \\
\hline Hypertension & 143 & 21.7 & $1.5(1.1-2.0)$ & 0.021 \\
\hline Epilepsy & 64 & 25.0 & $1.7(1.1-2.6)$ & 0.026 \\
\hline Gyn. Disease & 1122 & 17.5 & $1.2(1.0-1.4)$ & 0.020 \\
\hline Lung disease & 1950 & 16.6 & $1.1(1.0-1.2)$ & 0.040 \\
\hline Malaria & 12258 & 14.9 & $1.0(0.9-1.1)$ & 0.899 \\
\hline Anaemia & 406 & 17.0 & $1.2(0.9-1.5)$ & 0.267 \\
\hline Tuberculosis & 77 & 18.2 & $1.3(0.7-2.2)$ & 0.703 \\
\hline \multicolumn{5}{|l|}{ During pregnancy ${ }^{a}$} \\
\hline No ANC attendance & 137 & 34.3 & $2.3(1.8-2.9)$ & $<0.0001$ \\
\hline Referred to $\mathrm{ANC}^{\S}$ & 2284 & 21.0 & $1.5(1.4-1.6)$ & $<0.0001$ \\
\hline ANC $<5$ visits & 13168 & 16.2 & $1.3(1.2-1.4)$ & $<0.0001$ \\
\hline Anaemia & 449 & 18.3 & $1.2(1.0-1.5)$ & 0.050 \\
\hline Gestational Diabetic & 17 & 47.1 & $3.1(1.9-5.2)$ & $<0.0001$ \\
\hline Hypertension & 72 & 30.6 & $2.0(1.4-2.9)$ & $<0.0001$ \\
\hline Preeclampsia & 711 & 32.1 & $2.2(2.0-2.5)$ & $<0.0001$ \\
\hline Eclampsia & 27 & 70.4 & $4.7(3.7-6.0)$ & $<0.0001$ \\
\hline Bleeding & 239 & 23 & $1.5(1.2-2.0)$ & $<0.0001$ \\
\hline Malaria & 4314 & 14.4 & $1.0(0.9-1.0)$ & 0.167 \\
\hline Tuberculosis & 414 & 15.0 & $1.0(0.8-1.3)$ & 0.969 \\
\hline HIV infection & 784 & 16.1 & $1.0(0.8-1.1)$ & 0.528 \\
\hline \multicolumn{5}{|l|}{ Complications $^{\mathrm{a}}$} \\
\hline Abruptio placenta & 29 & 65.5 & $4.4(3.4-5.7)$ & $<0.0001$ \\
\hline PROM & 468 & 54.7 & $3.9(3.5-4.2)$ & $<0.0001$ \\
\hline Bleeding $>500 \mathrm{mls}$ & 36 & 33.3 & $2.2(1.4-3.5)$ & 0.001 \\
\hline Placenta previa & 51 & 45.1 & $3.0(2.2-4.1)$ & $<0.0001$ \\
\hline Caesarean section & 6472 & 24.2 & $2.3(2.2-2.5)$ & $<0.0001$ \\
\hline Other Vaginal delivery & 317 & 33.4 & $3.2(2.7-3.8)$ & $<0.0001$ \\
\hline Other unspecified & 373 & 24.7 & $1.7(1.4-2.0)$ & $<0.0001$ \\
\hline
\end{tabular}

a- Numbers for reference categories not given, each variable had complete data

$\S$ - First ANC visit triggered by health workers

preterm delivery, Apgar score and sex, and were as expected strongly related to neonatal transfer. Although the causal effect of birth weight is controversial [19] low birth weight is a good predictor of need for neonatal care. Low birth weight has been proposed to contribute to $40-80 \%$ of neonatal morbidity and mortality $[20,21]$. Preterm delivery is estimated to account for $28 \%$ of all neonatal deaths [20].

We also found a very high admission rate of newborns with a birth weight above $4000 \mathrm{~g}$. Fetal macrosomia is associated with obstetric complications and neonatal morbidity such as injuries, respiratory distress and hypoglycaemia. Observation for transient or persistent hypoglycaemia is a common reason for admission of high birth weight babies to NCU [22]. At KCMC, such babies will be discharged within 24 hours if there is no risk of persistent hypoglycemia and the blood glucose level is normal. The outcome is in general good for these babies, and one may speculate whether observation without transfer to NCU for many of these babies would represent a better use of resources.

In general, male neonatal morbidity exceeds female morbidity, partly due to a higher occurrence of preterm birth and other neonatal risk factors [23]. The male-tofemale ratio of transfer 1.24, declining to 1.18 in the adjusted analyses, corresponds well with the established higher risk in males, and does not indicate a difference in care according to infant sex. 
Table 3 Transfer to neonatal care unit $(n=3190)$ among 21206 live-born according to newborn health conditions

\begin{tabular}{|c|c|c|c|c|}
\hline Risk factors ${ }^{x}$ & $\begin{array}{l}\text { Number } \\
\text { live-born } \\
\text { deliveries }\end{array}$ & $\begin{array}{l}\text { Proportion (\%) } \\
\text { live-born babies } \\
\text { transferred to NCU }\end{array}$ & RR $(95 \% \mathrm{Cl})$ & p-value \\
\hline Birth weight (g) & & & & $<0.0001$ \\
\hline 500-1499 & 173 & 95.4 & $9.8(9.3-10.4)$ & \\
\hline $1500-2499$ & 1652 & 41.5 & $4.3(4.0-4.6)$ & \\
\hline 2500-3999 & 18607 & 9.7 & & \\
\hline $4000-6000$ & 714 & 69.7 & $7.2(6.7-7.7)$ & \\
\hline Apgar score 5 min & & & & $<0.0001$ \\
\hline$<7$ & 442 & 91.9 & $6.9(6.6-7.2)$ & \\
\hline $7+$ & 20590 & 13.4 & & \\
\hline Gestation age (weeks) & & & & $<0.0001$ \\
\hline $25-33$ & 447 & 70.5 & $5.6(5.2-6.1)$ & \\
\hline $34-36$ & 1401 & 27.3 & $2.2(2.0-2.4)$ & \\
\hline $37+$ & 17603 & 12.5 & 1.0 & \\
\hline Presentation & & & & $<0.0001$ \\
\hline Cephalic & 20862 & 14.8 & 1.0 & \\
\hline Breech & 238 & 28.2 & $1.9(1.6-2.3)$ & \\
\hline Transverse & 28 & 21.4 & $1.5(0.7-3.0)$ & \\
\hline Sex & & & & $<0.0001$ \\
\hline Male & 10904 & 16.6 & $1.2(1.2-1.3)$ & \\
\hline Female & 10162 & 13.3 & 1.0 & \\
\hline
\end{tabular}

$x$-The total in some variables does not sum to 21206 due to missing data

\section{Pregnancy, labour and delivery}

Risk of neonatal transfer was high in mothers with preeclampsia, eclampsia and abruption placenta, however no or weak effects were observed after inclusion of neonatal factors in the model. Hypertensive conditions in pregnancy are associated with preterm birth and low birth weight [15,24-27], and many cases of abruption placenta occur at a low gestational age, which explain the indirect association between these complications and neonatal transfer. The direct cause of transfer would be the preterm birth.

Other conditions, such as premature rupture of membrane, caesarean section and operative vaginal delivery, showed a high risk of neonatal transfer also after accounting for the neonatal condition of the baby. The high rate of transfer for babies born with mothers having PROM is similar to what is reported elsewhere [15]. Premature rupture of the membrane (PROM) is associated with preterm delivery and low birth weight $[15,27]$. A previous study at KCMC reported a high prevalence (38\%) of low birth weight babies after PROM [27]. Such babies are at higher risk of developing neonatal infection. Antibiotic prophylaxis given to mothers with PROM has shown to reduce risk of infection in the newborn $[28,29]$. The high transfer rate after PROM in our data is likely to be explained by the fact that a majority of mothers with a history of PROM did not receive antibiotic prophylaxis prior to delivery, due to late arrival to the centre.
Mothers with less than five antenatal care visits were more likely to have their baby transferred and this association persisted after we took into account our measures of the condition of the newborn. Amount of antenatal care plays a role in neonatal outcome [30-32], and each additional ANC visit has previously been found to offer a protective effect on neonatal outcome [31]. When the mother had been referred for antenatal care, however, the risk of transfer was increased.

\section{Pre pregnancy factors}

Among diseases that the mothers had before the pregnancy, only lung disease remained significantly associated with neonatal transfer when pregnancy conditions and neonatal conditions were accounted for (Table 4, model C). Pre-gestational diabetes was strongly related to transfer in models $\mathrm{A}$ and $\mathrm{B}$, but the association disappeared after accounting for the neonatal conditions in model C. Noteworthy, gestational diabetes had a weak and non-significant association with transfer, and the relative risk was not affected by adjustment for neonatal factors. The low risk of transfer in babies born to mothers with gestational diabetes compared to babies of mothers with pre-gestational diabetes is also reported elsewhere $[5,15,33]$.

Women giving birth to their first child and single mothers were more likely to have their baby transferred to NCU, also after accounting for pregnancy conditions and neonatal conditions. Birth to a first child and single 
Table 4 Linear regression model risk factors for neonatal transfer to neonatal care unit

\begin{tabular}{|c|c|c|c|}
\hline & Model $A^{a}$ & Model $B^{a}$ & Model $C^{a}$ \\
\hline Risk factors & RR (95\%Cl) & RR $(95 \% \mathrm{Cl})$ & RR $(95 \% \mathrm{Cl})$ \\
\hline \multicolumn{4}{|l|}{ Pre-pregnancy factors } \\
\hline \multicolumn{4}{|c|}{ Maternal age (Ref. 18-25 years) } \\
\hline Under 18 years & $1.0(0.8-1.4)$ & $1.0(0.8-1.4)$ & $0.9(0.7-1.2)$ \\
\hline $26-35$ years & $1.3(1.1-1.4)^{* *}$ & $1.2(1.1-1.3)^{* *}$ & $1.2(1.1-1.3)^{* *}$ \\
\hline Over 35 years & $1.1(0.9-1.3)$ & $1.0(0.8-1.3)$ & $1.0(0.8-1.2)$ \\
\hline \multicolumn{4}{|l|}{ Birth order (Ref. $2^{\text {nd }}$ child) } \\
\hline $1^{\text {st }}$ child & $1.3(1.2-1.4)^{* *}$ & $1.3(1.2-1.5)^{* *}$ & $1.4(1.2-1.5)^{* *}$ \\
\hline $3^{\text {rd }}$ child & $1.0(0.8-1.1)$ & $1.0(0.9-1.1)$ & $1.0(0.9-1.1)$ \\
\hline $4^{\text {th }}$ or more & $1.2(1.0-1.3)$ & $1.3(1.1-1.4)^{* *}$ & $1.1(1.0-1.3)$ \\
\hline \multicolumn{4}{|l|}{ Body mass index(Ref 18.5-24.9) } \\
\hline Underweight $(<18.5)$ & $1.0(0.9-1.2)$ & $1.0(0.9-1.2)$ & $1.0(0.9-1.2)$ \\
\hline Overweight (25-29.9) & $1.2(1.1-1.3)^{* *}$ & $1.2(1.0-1.3)^{* *}$ & $1.1(1.0-1.2)$ \\
\hline Obesity(30+) & $1.3(1.1-1.5)^{* *}$ & $1.2(1.1-1.4)^{* *}$ & $1.1(1.0-1.3)$ \\
\hline Single marital status & $1.3(1.1-1.5)^{* *}$ & $1.2(1.1-1.4)^{*}$ & $1.2(1.0-1.3)^{*}$ \\
\hline Body height $<150 \mathrm{~cm}$ & $1.2(1.1-1.4)^{*}$ & $1.0(0.9-1.2)$ & $1.1 \mathrm{c}(0.9-1.2)$ \\
\hline \multicolumn{4}{|l|}{ Paternal age (Ref 26-35 years) } \\
\hline Under 26 years & $1.2(1.0-1.3)$ & $1.1(1.0-1.3)$ & $1.2(1.0-1.3)^{*}$ \\
\hline $36-45$ years & $1.0(0.9-1.1)$ & $0.9(0.8-1.0)$ & $0.9(0.8-1.1)$ \\
\hline Over 45 years & $1.1(0.9-1.4)$ & $1.1(0.9-1.4)$ & $1.1(0.9-1.3)$ \\
\hline \multicolumn{4}{|c|}{ Father's education (Ref sec/high) } \\
\hline No education & $1.2(0.7-2.3)$ & $0.8(0.5-1.5)$ & $0.5(0.3-0.9)^{*}$ \\
\hline Primary school & $1.0(0.9-1.1)$ & $1.0(0.9-1.1)$ & $1.0(0.9-1.1)$ \\
\hline Pre-gestational diabetic & $4.4(3.3-5.8)^{* *}$ & $3.5(2.6-4.7)^{* *}$ & $1.6(0.7-3.3)$ \\
\hline Maternal Lung disease & $1.2(1.1-1.4)^{* *}$ & $1.2(1.1-1.4)^{* *}$ & $1.2(1.0-1.3)^{*}$ \\
\hline Maternal Epilepsy & $1.6(1.0-2.6)$ & $1.9(1.2-2.9)^{* *}$ & $1.4(0.9-2.2)$ \\
\hline Not boiling drinking water & $1.2(1.1-1.3)^{* *}$ & $1.1(1.0-1.3)^{* *}$ & $1.1(1.0-1.2)$ \\
\hline
\end{tabular}

\section{Pregnancy, labour and delivery}

Mother referred to $\mathrm{ANC}^{\S}$

ANC $<5$ visits

Gestational Diabetic

Hypertension

Preeclampsia

Eclampsia

Abruptio placenta

Premature rupture of membrane

Caesarian section

Other vaginal delivery

Other unspecified complications

\section{Neonatal factors}

Birth weight $>4000 \mathrm{~g}$

Birth Weight 1500-2500 g

Birth weight $<1500 \mathrm{~g}$

Gestational age below 34 weeks

Gestational age 34-36 weeks

Five minutes Apgar score $<7$

Male sex

$\begin{array}{ll}1.3(1.1-1.4)^{* *} & 1.2(1.0-1.3)^{*} \\ 1.3(1.2-1.4) & 1.2(1.1-1.3)^{* *} \\ 1.4(0.6-3.4) & 1.4(0.5-4.5) \\ 1.5(0.9-2.4) & 1.2(0.7-1.9) \\ 2.0(1.7-2.3)^{* *} & 1.3(1.1-1.5)^{* *} \\ 2.8(1.7-4.4)^{* *} & 0.9(0.6-1.6) \\ 2.6(1.6-4.1)^{* *} & 1.1(0.7-1.8) \\ 2.9(2.6-3.4)^{* *} & 2.3(1.9-2.7)^{*} \\ 2.1(1.9-2.3)^{* *} & 1.9(1.8-2.1)^{* *} \\ 2.9(2.3-3.6)^{* *} & 2.2(1.7-2.9)^{* *} \\ 1.8(1.4-2.3)^{* *} & 1.5(1.2-1.9)^{* *}\end{array}$

*p-value less than 0.05

**p-value less than 0.01

${ }^{a}$ In each step variables entered were all which had $p$-value of $<0.1$ in univariable analysis including maternal age although $p$-value was slightly above 0.1 (0.106). The lowest risk category in each group was used as a reference. Results are presented for all variables which were significant at least once in any of the three steps.

Model A, first step; adjusted for pre pregnancy factors

Model B, second step; variables in model A plus conditions in pregnancy, labor and delivery

Model C, third step; variables in model B plus neonatal factors

$\S$ - First ANC visit triggered by health workers 
motherhood are classical risk factors for neonatal morbidity and mortality $[9,10,12,18,34,35]$. However, the $40 \%$ higher risk of admission for a first born child in the fully adjusted model (model C), is higher than what one would expect according to previous knowledge on morbidity and mortality associated with first delivery. In a previous study from the same hospital, perinatal mortality was not associated with birth order except for a higher perinatal mortality in offsprings of mothers with three or more previous pregnancies [11]. To further elaborate this finding, we performed a regression analysis with a finer categorization of Apgar score. In this model, the parity effect was still statistically significant, however reduced. In a setting with limited obstetric services, the generally higher neonatal stress on first born babies might be even more evident.

In line with previous findings [36-38] we found that overweight and in particular obese mothers had a high risk of having their baby transferred to NCU. Maternal obesity is associated with some pregnancy complications [33,36-40] and overweight or obese mothers are more likely to have high birth weight babies $[37,38,40]$. A meta-analysis review showed a lower risk of low birth weight among babies of overweight or obese mothers compared to normal weight mothers, however the risk of very low birth weight and extremely low birth weight was increased due to more induced preterm deliveries in overweight or obese mothers [41]. In our data, the association of neonatal transfer associated with maternal overweight and obesity was weakened but still statistically significant after adjustment for pregnancy conditions, however disappeared after adjustment for neonatal conditions. Hence, pregnancy conditions and neonatal conditions seem to be mediators in the association between maternal overweight and neonatal transfer. A similar pattern was seen for mothers of short stature, where an increased risk seen in model A seemed to be linked to a higher rate of pregnancy complications for these mothers.

Drinking unboiled water was one of the factors associated with neonatal transfer. Waterborne disease including diarrhoea and dysentery is prevalent in Tanzania, therefore, it is recommended to boil water for drinking including tap water. In our study $92 \%$ of the participants used tap water, however only $31 \%$ boiled water for drinking. In a study from Tanzania, lack of boiling water prior to consumption was more common in households with low income, and lack of proper knowledge on the importance of how to handle and store water safely was associated with E.coli occurrence [42]. Both ignorance and poverty might be the major barriers to boiling drinking water.

Lack of paternal education was associated with a low chance of neonatal transfer ( $\mathrm{RR}=0.5$; 95\% CI: 0.3-0.9) in the fully adjusted model. Although our results should be interpreted with care due to the low numbers (110 fathers with no education) and a confidence interval close to one, the findings could reflect low focus on neonatal health care in deprived families. A previous study using the same birth registry reported that paternal socio-demographic factors seemed to be more important predictors of perinatal mortality than maternal socio-demographic factors in this area [11]. However, such an interpretation is not compatible with the principle that transfer mechanisms should be unaffected by parental and family influence.

\section{Strengths and limitations}

The study was based on a hospital based birth registry, where data are carefully collected according to standardized procedures, ensuring complete coverage of births on a daily basis including weekends and holidays. Information was collected by designated midwives using a structured questionnaire-based interview, and medical records were used to verify the information from the questionnaire. The sample size was relatively large and enabled us to study many risk factors in relation to neonatal transfer. Hence, the data allowed us to study the relationship between socio-demographic characteristics, maternal health and complications during delivery, and neonatal characteristics, with transfer to neonatal intensive care unit. Selection bias was reduced by excluding all medically indicated referral births from rural areas where the mother would not probably deliver at KCMC if not referred. The excluded cases accounted for $52 \%$ of all referrals and $75 \%$ of all medical referrals.

About 29\% of the deliveries in the Kilimanjaro region occur at home [20], and the study results may not be representative of the entire population within the area. Although women who give birth at the hospital largely differ with respect to socio-demographic status, the socio-demographic variation in the community may be even larger and towards a less privileged population. It is therefore possible that the observed risks are underestimated as compared to the region.

We applied an analytical approach where the various classes of variables were included in regression models through three steps. The purpose of this was to identify which factors that mediated any association with transfer. Our analyses are based on a limited set of variables, and there may be important risk factors of neonatal transfer that we have not been able to account for. Hence, the effects obtained in the models may represent a mixture of effects of the studied factors and effects of factors not accounted for. In particular, our measures of the condition of the newborn were probably too crude to fully account for the clinical judgement of the baby's condition and the need for transfer. 
Despite these limitations, we believe that our study, based on structured collection of information with a hospital based design combined with careful considerations of possible biases, represent findings of importance. True population data are difficult to collect in sub-Saharan Africa. Investment in competence building and data collection should start with key hospitals, and efforts should be done to include well-defined populations, in order to generate relevant and representative data to address the important public health issues within the general population.

\section{Conclusions}

Our study has demonstrated the combined effect of socio-demographic, maternal health conditions and neonatal factors in predicting transfer to NCU. The relationship between socio-demographic, maternal health characteristics and neonatal factors observed in this study reflects traditionally known predictors of neonatal morbidity and mortality. As for the pre-pregnancy factors, most of the associations with transfer were accounted for by pregnancy complications and neonatal factors. An exception from this was a possibly reduced use of transfer for babies of non-educated fathers. The potential effect of paternal social status both on neonatal health and on access to health care for mother and baby needs more attention. Another exception that needs to be further explored is the $40 \%$ higher rate of transfer among first born babies. With respect to neonatal factors, one might speculate whether the high number of babies above $4000 \mathrm{~g}$ transferred to the NCU represents an optimal use of resources, as the outcome of these babies is in general good.

\section{Acknowledgements}

We acknowledge the Norwegian Council for Higher education program for Development Research (NUFU) for funds support. We thank the staff of the birth registry department in Norway for ongoing supervision and technical support for the KCMC birth registry. We also thank the birth registry team, labour ward and NCU staff at KCMC for their support in data collection, and in taking care of mothers and their newborns. To our participants' mothers who delivered at KCMC during the period of data collection, we say "Thank you" for y our consent and participation in giving needed information.

\section{Author details}

${ }^{1}$ Kilimanjaro Christian Medical Centre and Kilimanjaro Christian Medical College, P.O Box 3010, Moshi, Tanzania. ${ }^{2}$ Department of Public Health and Primary Health Care, University of Bergen, P.O Box 7804, 5020 Bergen, Norway. ${ }^{3}$ Centre for International Health, University of Bergen, P.O Box 7804, 5020 Bergen, Norway. ${ }^{4}$ Norwegian Institute of Public Health, Division of Epidemiology, Oslo, Norway. ${ }^{5}$ Kilimanjaro Clinical Research Institute, P.O Box 2236 Moshi, Tanzania.

\section{Authors' contributions}

BTM: Study design, methodology, data analysis and manuscript writing. RTL, GSK, RO, GK, AKD: Study design, methodology, manuscript writing. All authors approved the final manuscript.

\section{Competing interests}

The authors declare that they have no competing interests.

Received: 10 May 2011 Accepted: 4 October 2011

Published: 4 October 2011

\section{References}

1. Zupan J: Perinatal Mortality in Developing Countries. N Eng J Med 2005, 352(20):2047-2048

2. National Bureau of Statistics, Tanzania and ORC Macro: Tanzania demographic and health survey 2004-05. Dar es Salaam, Tanzania. National Bureau of Statistics and Calverton, MD, USA: ORCMacro 2005.

3. Masanja H, Savigny D, Smithson P, Schellenberg J, John T, Mbuya C, Upunda G, Boerma T, Victora C, Smith T, Mshinda H: Child survival gains in Tanzania: analysis of data from demographic and health surveys. Lancet 2008, 371:1276-1283.

4. Manning D, Brewster B, Bundred P: Social deprivation and admission for neonatal care. Arch Dis Child Fetal Neonatal Ed 2005, 90(4):F337-343.

5. Phung $\mathrm{H}$, Bauman A, Tran M, Young L, MCDonald J, Michel L, Hillman K: Factors that influence special care nursery admissions to a district hospital in South-western Sydney. J Paediatr Child Health 2005, 41(3):119-124

6. Jonas O, Roder D, Chan A: The Association of low Socioeconomic status in Metropolitan Adelaide with maternal demographic and Obstetric characteristics and Pregnancy Outcomes. Eur J Epidemiol 1992, 8(5):708-714.

7. Yunis K, Beydoun H, Khogali M, Alameh M, Tamim H: Low socioeconomic status and neonatal outcomes in an urban population in a developing country. J Matern Fetal Neonatal Med 2003, 14(5):338-343.

8. Valero de Bernabe' J, Soriano T, Albaladejo R, Juarranz M, Calle ME, Martinez D, Dominguez-Rojas V: Risk factors for low birth weight: a review. Eur J Obstet Gynecol Reprod Biol 2004, 116:3-15.

9. Elshibly EM, Schmalisch G: The effect of maternal anthropometric characteristics and social factors on gestational age and birth weight in Sudanese newborn infants. BMC Public Health 2008, 8:244.

10. Grjibovski A, Bygren LO, Svartbo B: Socio-demographic determinants of poor infant outcome in north-west Russia. Paediatr Perinat Epidemio/ 2002, 16(3):255-262.

11. Habib AN, Lie RT, Oneko O, Shao J, Bergsjø P, Daltveit AK: Sociodemographic characteristics and perinatal mortality among singletons in North East Tanzania: a registry-based study. J Epidemiol Community Health 2008, 62:960-965.

12. Forssas E, Gissler M, Sihvonen M, Hemminki E: Maternal predictors of perinatal mortality: the role of birth weight. Int J Epidemiol 1999, 28:475-478.

13. Hinderaker SG, Olsen BE, Bergsjø PB, Gasheka P, Lie RT, Kvåle G: Perinatal Mortality in Northern Rural Tanzania. J Health Popul Nutr 2003, 21(1):8-17.

14. Houweling TA, Kunst AE: Socio-economic inequalities in childhood mortality in low- and middle-income countries: a review of the international evidence. Br Med Bull 2010, 93(1):7-26.

15. Ross MG, Downey AC, Bemis-Heys R, Nguyen M, Jacques DL, Stanziano G: Prediction by maternal risk factors of neonatal intensive care admissions: Evaluation of $>59,000$ women in national managed care programs. Am J Obstet Gynecol 1999, 181(4):835-842.

16. Jahn A, Kowalewski M, Kimatta SS: Obstetric care in southern Tanzania: does it reach those in need? Trop Med Int Health 1998, 3(11):926-932.

17. Schmidt $\mathrm{C}$, Kohlmann $\mathrm{T}$ : When to use the odds ratio or the relative risk? Int J Public Health 2008, 53(3):165-167.

18. Samms-Vaughan ME, Ashley DC, McCaw-Binns AM: Factors determining admission to NCU in Jamaica. Paediatr Perinat Epidemiol 2001, 15(2):100-105.

19. Wilcox AJ: On the importance-and the unimportance- of birthweight. Int J Epidemiol 2001, 30(6):1233-1241.

20. Lawn JE, Cousens S, Zupan J: 4 million neonatal deaths: When? Where? Why? Lancet 2005, 365(9462):891-900.

21. World Health Organization: The world health report make every mother and child count. Geneva 2005.

22. Gillean JR, Coonrod DV, Russ R, Bay RC: Big infants in the neonatal intensive care unit. Am J Obstet Gynecol 2005, 192(6):1948-1953.22. 
23. Zeitlin J, Saurel-Cubizolles M-J, de Mouzon J, Rivera L, Ancel P-Y, Blondel B, Kaminski M: Fetal sex and preterm birth: are males at greater risk? Hum Reprod 2002, 17(10):2762-2768.

24. Ayaz A, Muhammad T, Hussain SA, Habib S: Neonatal outcome in preeclamptic patients. J Ayub Med Coll Abbottabad 2009, 21(2):53-55.

25. Jehan A, Musarrat J, Nadra S: Perinatal outcome in pregnancy induced hypertensive mothers. Pak Armed Forces Med J 2004, 54(8):76-78.25.

26. Sibai BM, Lindheimer M, Hauth J, Caritis S, VanDorsten P, Klebanoff M, MacPherson C, Landon M, Miodovnik M, Paul R, Meis P, Dombrowski M: Risk factors for Preeclampsia, abruptio placentae, and adverse neonatal outcomes among women with chronic hypertension. N Eng J Med 2010, 339(10):667-671.

27. Siza JE: Risk factors associated with low birth weight of neonates among pregnant women attending a referral hospital in northern Tanzania. Tanzan Health Res Bull 2008, 10(1):1-8.

28. Egarter $C$, Leitich $H$, Karas $H$, Wieser F, Husslein $P$, Kaider A, Schemper M: Antibiotic treatment in preterm premature rupture of membranes and neonatal morbidity: A metaanalysis. Am J Obstet Gynecol 1996, 174(2):589-597.

29. Cousens S, Blencowe H, Gravett M, Lawn JE: Antibiotics for pre-term prelabour rupture of membranes, prevention of neonatal deaths due to complications of pre-term birth and infection. Int J Epdemiol 2010, 39: i134-143.

30. Owolabi AT, Fatusi AO, Kuti O, Adeyemi A, Faturoti SO, Obiajuwa PO: Maternal complications and perinatal outcomes in booked and unbooked Nigerian mothers. Singapore Med J 2008, 49(7):526-531.

31. Brown C, Sohani S, Khan K, Lilford R, Mukhwana W: Antenatal care and perinatal outcomes in Kwale district, Kenya. BMC Pregnancy Childbirth $2008,8(1): 2$

32. Blondel $B$, Dutlih $P$, Delour $M$, Uzan S: Poor antenatal care and pregnancy outcome. Eur J Obstet Gynecol Reprod Biol 1993, 50:191-196.

33. Ray JG, Vermeulen MJ, Shapiro JL, Kenshole AB: Maternal and neonatal outcomes in pregestational and gestational diabetes mellitus, and the influence of maternal obesity and weight gain: the DEPOSIT study. Q J Med 2001, 94(7):347-356.

34. Simiyu DE: Morbidity and mortality of low birthweight infants in the newborn unit of Kenyatta National hospital Nairobi. East Afr Med J 2004 81(7):367-374.

35. Wasunna A, Mohammed K: Morbidity and outcome of low birthweight babies of adolescent mothers at Kenyatta National Hospital, Nairobi. East Afr Med J 2002, 79(10):539-542.

36. Dixit A, Girling JC: Obesity and pregnancy. J Obstet Gynaecol 2008, 28(1):14-23.

37. Ramachenderan J, Bradford J, McLean M: Maternal obesity and pregnancy complications: a review. Aust NZ J Obstet Gynaecol 2008, 43(3):228-235.

38. Yogev $Y$, Visser GHA: Obesity, gestational diabetes and pregnancy outcome. Semin Fetal Neonatal Med 2009, 14(2):77-84.

39. Chen M, Mcniff C, Madan J, et al: Maternal obesity and neonatal Apgar scores. J Matern Fetal Neonatal Med 2010, 23(1):89-95.

40. Ehrenberg HM, Mercer BM, Catalano PM: The influence of obesity and diabetes on the prevalence of macrosomia. Am J Obstet Gynecol 2004, 191:964-968.

41. McDonald SD, Han Z, Mulla S, Beyene J: Overweight and obesity in mothers and risk of preterm birth and low birth weight infants: systematic review and meta-analyses. BMJ 2010, 341:c3428.

42. Hartstone LC, Knight J, Riley JJ: Water in Tanzania: A Role for Extension. J Int Agr Ext Educ 2006, 13(1):59-71.

\section{Pre-publication history}

The pre-publication history for this paper can be accessed here: http://www.biomedcentral.com/1471-2393/11/68/prepub

doi:10.1186/1471-2393-11-68

Cite this article as: Mmbaga et al: Transfer of newborns to neonatal care unit: a registry based study in Northern Tanzania. BMC Pregnancy and Childbirth 2011 11:68.

\section{Submit your next manuscript to BioMed Central and take full advantage of:}

- Convenient online submission

- Thorough peer review

- No space constraints or color figure charges

- Immediate publication on acceptance

- Inclusion in PubMed, CAS, Scopus and Google Scholar

- Research which is freely available for redistribution

Submit your manuscript at www.biomedcentral.com/submit
Biomed Central 